\title{
Investigation of Sintering Temperature on Attrition Resistance of Highly Porous Diatomite Based Material
}

\author{
Noemie van Garderen, Frank J. Clemens, Dagobert Scharf, Thomas Graule \\ Empa, Swiss Federal Laboratories for Materials Testing and Research, Laboratory for High Performance Ceramics, \\ Ueberlandstrasse 129, 8600 Dübendorf, Switzerland
}

\begin{abstract}
Highly porous diatomite based granulates with a diameter of $500 \mu \mathrm{m}$ have been produced by an extrusion method. In order to investigate the relation between microstructure, phase composition and attrition resistance of the final product, the granulates were sintered between 800 and $1300^{\circ} \mathrm{C}$. Mean pore size of the granulates was evaluated by $\mathrm{Hg}$-porosimetry. An increase of the pore size is observed in the range of $3.6 \mathrm{~nm}$ to $40 \mu \mathrm{m}$ with increasing sintering temperature. Higher mean pore radii of $1.6 \mu \mathrm{m}$ and $5.7 \mu \mathrm{m}$ obtained by sintering at 800 and $1300^{\circ} \mathrm{C}$ respectively. X-ray diffraction shows that mullite phase appears at $1100^{\circ} \mathrm{C}$ due to the presence of clay. At $1100^{\circ} \mathrm{C}$ diatomite (amorphous silicate) started to transform into $\alpha$ cristobalite. Attrition resistance was determined by evaluating the amount of ground material passed through a sieve with a predefined mesh size. It was observed that a material sintered at high temperature leads to an increase of attrition resistance due to the decrease of total porosities and phase transformation. Due to the reason that attrition resistance significantly increased by sintering the granulates at higher temperature, a so called attrition resistance index was determined in order to compare all the different attrition resistance values. This attrition resistance index was determined by using the exponential component of the equation obtained from attrition resistance curves. It permits comparison of the attrition behaviour without a time influence.
\end{abstract}

Keywords: Clay, Diatomite, Sintering temperature, Microstructure, Attrition resistance PACS: 81.05. Je

\section{INTRODUCTION}

Porous ceramics have been widely studied during the last decades for separation applications, to improve thermal resistance, structural stability and mechanical strength. Diatomite is a sedimentary rock resulting from siliceous fossilized skeleton of diatoms $\left(\mathrm{SiO}_{2}\right.$. $\mathrm{nH}_{2} \mathrm{O}$ and crystallised silica), unicellular algae, that existed during tertiary and quaternary periods. It is mainly used as a filter, filler or mild abrasive material due to its porosities. Losic et al. reported a complete introduction about nano and microstructure of diatoms and showed how promising this material is for high technologies (e.g. microelectronics, chemo- and biosensoring, transducers,etc.) [1]. Liang studied rheology and die swell behaviour during extrusion of polypropylene/ diatomite feedstocks [2]. However this area is not widely reported yet. Indeed, diatomite is mostly known as an additive material, for example in extrusion as an anti-blocking agent. Aderdour et al. characterized diatomite samples sintered between 1050 and $1350^{\circ} \mathrm{C}$ with compressive strength and by scanning electron microscopy (SEM) [3]. They concluded that the increase of stiffness is due to an increase of the density.

Attrition has been defined as ,the unwanted breakdown of particles within a process (this includes both abrasion and fragmentation)" by the British Standard (BS 2955:1958). Several techniques permitting to characterize attrition properties were already referenced by Bemrose and Bridgwater [4]. It is worthwhile to note that knowing the attrition resistance of a material is useful in any manufacture that use powders, e.g. chemical industries with the use of catalysts, cement industries. 
This work is focused on the development of attrition resistance of high open porosity granulates based on a diatomite earth and clay mixture. These granulates were shaped by using a piston extruder and can be used for chemical, catalytic or filtration applications. The purpose of this work was to develop a highly open porous structure and to investigate the influence of sintering temperature on attrition resistance and microstructure. Due to the attrition results a so called attrition resistance index was used to compare the significant different results of the materials.

\section{EXPERIMENTAL}

\section{Raw materials and processing route}

2 diatomite materials (Celite, World Minerals Inc., USA) with a measured specific surface area of 8.8 and $2.7 \mathrm{~m}^{2} / \mathrm{g}$ were selected for this study. Median particle size given by the supplier of 14 and $15 \mu \mathrm{m}$ respectively with a median pore size of 2.2 and $3.5 \mu \mathrm{m}$ were used to achieve a high porous structure after sintering. Both diatomites are composed of approximately $90 \% \mathrm{SiO}_{2}$ and $4 \% \quad \mathrm{Al}_{2} \mathrm{O}_{3}$. A kaolinite based clay material (Amberger Kaolinwerke, Germany) was used as an inorganic binder agent. Additionally some organic components (cellulose, oleic acid) were added to adjust plasticity and extrudability of the feedstocks.

The material was pre-mixed in a planetary mixer before adding liquid ingredients. After approximately 6 min of mixing time the material was filled in a piston extruder (Type 23216 DT-HS, Loomis, Germany). Feedstocks were extruded through a die with an orifice of $500 \mu \mathrm{m}$. The extruded parts were dried for 3 days at $60^{\circ} \mathrm{C}$ before grinding and sieving into granulates with a size between 180 and $500 \mu \mathrm{m}$.

Finally the samples were sintered at different temperatures: $800,1100,1200$ and $1300^{\circ} \mathrm{C}$ for $3 \mathrm{~h}$ in a furnace (PY 12H, Pyrotec).

The processing route is shown Fig. 1.

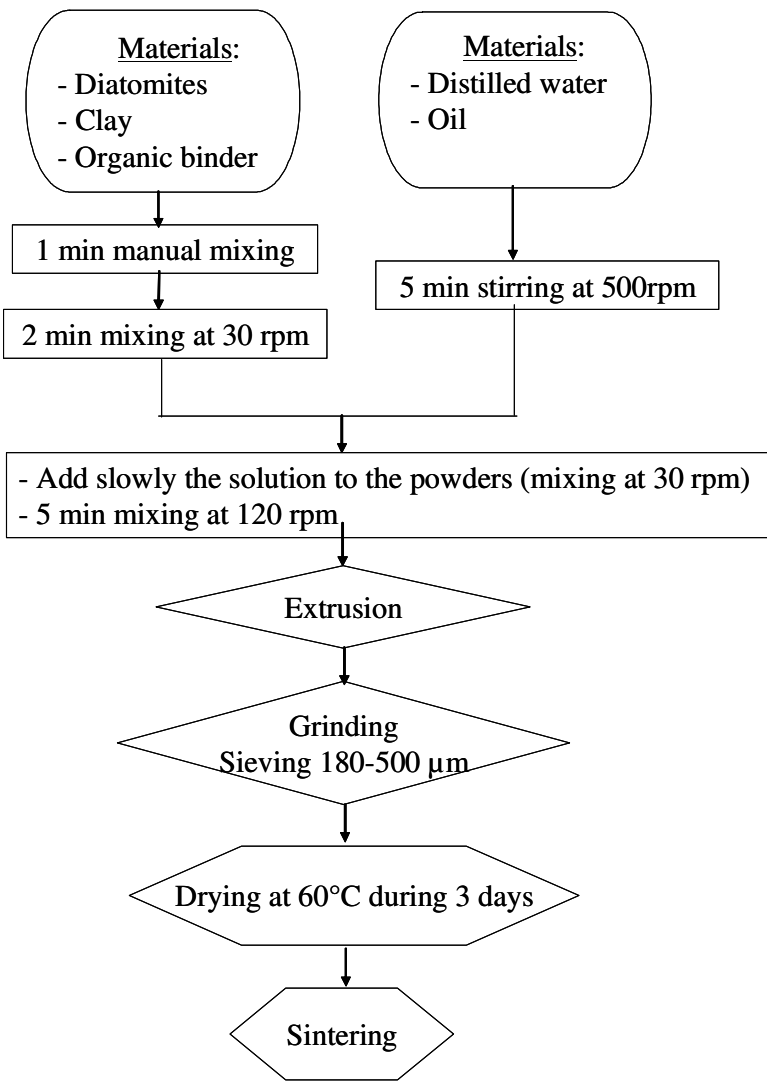

FIGURE 1. Processing route for the production of diatomite based granulates.

\section{Development of an attrition test}

An easy and reproducible test has been developed to be able to investigate attrition resistance of the produced granulates. This test was adapted from the ASTM Norm D 409D_409M-09 called "Standard test method for grindability of coal by hardgrove-machine method". The grindability test is generally made in a ball milling device [5].

The material is grinded by impact of balls due to the velocity enhanced by the rotation of the container. Neikov et al. explain that attrition occurs due to the accumulation of defects, which leads to some local concentration of stress [5]. Attrition behaviour is mainly influenced by the number, size and material of the balls, the sample volume, the volume and material of the container and the rotation speed and number of revolutions (attrition time) of the mill. 
Attrition tests were performed on samples sintered at different temperatures. They were done with 4 zirconium oxide balls (25 mm diameter) in a $250 \mathrm{ml}$ polyethylene bottle and with a ball milling machine (type RM1, Zoz GmbH). The rotation speed was fixed to 60 revolutions per minute. Approximately $4.8 \mathrm{~cm}^{3}$ of granulates were used. Around 85 vol. $\%$ of the bottle is free during attrition tests which permit a high impact of the balls on the material due to the velocity enhanced by its revolution. The material takes 2 vol.\% of the free space of the bottle (volume of the bottle minus the volume of the 4 balls) and the balls, 13 vol. $\%$.

The granulates were tested with different attrition times (numbers of revolutions).

\section{CHARACTERIZATION}

To investigate the geometrical density, samples with a diameter of $19 \mathrm{~mm}$ were additionally extruded and the density was calculated after measuring the dimension of the samples and their weight. Total porosity and average pore size was evaluated by a Mercury Intrusion Porosimeter (Pascal 140/440, Thermo Fisher). The surface tension and the contact angle of mercury were set to $0.480 \mathrm{~N} / \mathrm{m}$ and $140^{\circ}$ respectively. Scanning Electron Microscopy (SEM) was done with a TS $5136 \mathrm{MM}$ apparatus (Tescan) to characterize the microstructure of the diatomite samples. Chemical phases were analysed by a X'Pert Pro PW3040 X-ray powder diffractometer (PANanalytical) using $\mathrm{Cu}$ target $(\mathrm{K} \alpha, \lambda=0.15406 \mathrm{~nm})$ radiation at $45 \mathrm{kV}$ and $40 \mathrm{~mA}$ settings.

Bemrose and Bridgwater showed that attrition resistance can be characterized by "the percentage of powder reduced to less than a certain size in a specified time within a specified test apparatus" [4]. These certain particle size and attrition time have to be fixed in order to compare the results. Characterization of attrition resistance is usually done by comparing particle size distribution by laser diffraction of a material before and after performing the attrition test or by doing Brunauer, Emmett, Teller (BET) analysis. However, it was not possible to use one of these methods as the granulates are not dense (internal specific surface area) and fine particles from abrasion of the edges can occur ("fines") as explained by Stein et al. [6]. They divided attrition of particles into two main different aspects: first, the fragmentation of particles into parts of approximately similar size and secondly, into the creation of fine dust by abrasion of material from the edges of the granulates. In this last case, no significant decrease of granulate size will be seen by measuring laser diffraction of this material. Due to this reason, attrition resistance was measured by weighing the granulates passing through the sieve during wet sieving, instead of measuring the larger ones. Wet sieving was done by washing the $180 \mu \mathrm{m}$ mesh size sieve with water and drying afterwards at $120^{\circ} \mathrm{C}$ in an oven until complete drying (around $40 \mathrm{~h}$ ).

\section{Calculation of attrition resistance}

The attrition resistance was calculated by using Equation (1):

$$
\text { Attrition Resitance }=\frac{\left(m_{1}-m_{2}\right)}{m_{1}} \cdot 100
$$

Where:

$\mathrm{m}_{1}$ : total weight of the material used for attrition test. $\mathrm{m}_{2}$ : weight of the material passing through the $180 \mu \mathrm{m}$ sieve.

\section{RESULTS AND DISCUSSION}

\section{Geometrical densities}

Samples sintered at temperatures lower than $800^{\circ} \mathrm{C}$ didn't shrink, even if the main weight loss occurs below this temperature.

Figure 2 proves, as expected, that a high sintering temperature leads to an increase of sample densities. Increase of geometrical density is due to a decrease of the total porosity of the samples.

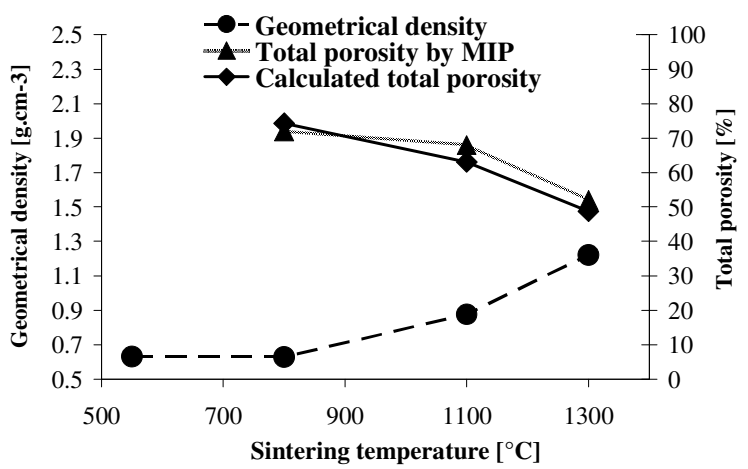

FIGURE 2. Influence of sintering temperature on geometrical density and total porosity. 
By comparing total porosity obtained by mercury intrusion porosimetry (MIP) and total porosity calculated by skeletal density obtained by $\mathrm{He}$ Pycnometry and geometrical density, we can conclude that even with samples sintered at $1300^{\circ} \mathrm{C}$ a highly open porous structure occurs.

\section{Porosities}

Mercury Intrusion Porosimetry (MIP) was used to determine the whole range of porosities, from $3.6 \mathrm{~nm}$ to $40 \mu \mathrm{m}$. This permits us to conclude the presence of meso and macro range porosities, following IUPAC terminology [7]. Pore size from 3 to $200 \mathrm{~nm}$ can also be confirmed by $\mathrm{N}_{2}$ adsorption by using the BarretJoyner-Halenda (BJH) method. The results correlated with the SEM pictures (Fig. 4).

A decrease of the total porosity is observed when we increase sintering temperature (as seen Fig. 2). This was confirmed by SEM. However, Fig. 3 shows that Pore Size Distribution (PSD) measured by MIP is increasing with increasing sintering temperature. We also verified the loss of smaller pores between 1100 and $1300^{\circ} \mathrm{C}$ by $\mathrm{BJH}$. It is assumed by the authors that at higher temperature, the numerous small pores of diatomites will disappear due to sintering and coalescence of this component.

Only pores between sintered diatomite and clay material (which transformed into mullite at $1100^{\circ} \mathrm{C}$ ) are still present and therefore the mean pore size increases with increasing sintering temperature until $1300^{\circ} \mathrm{C}$. This also explains why open porosity still occurs at higher sintering temperature.

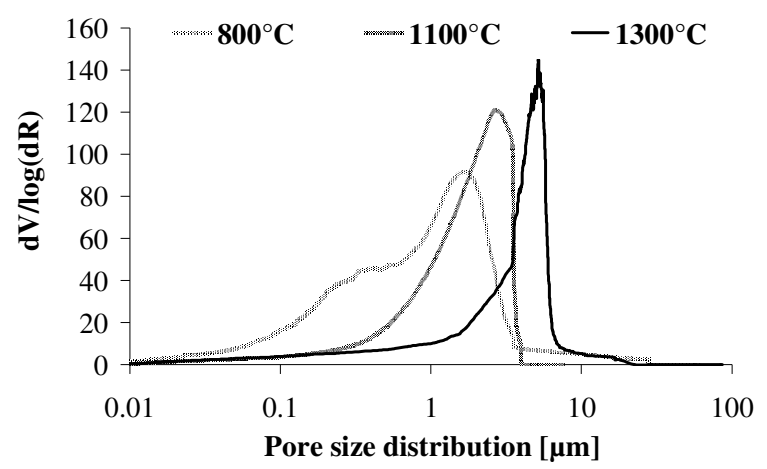

FIGURE 3. Pore size distribution of diatomite samples containing 48 vol.\% of clay, sintered at 800, 1100 and $1300^{\circ} \mathrm{C}$, measured by MIP.

\section{Scanning Electron Microsopy}

Figure 4 shows the SEM pictures of samples sintered at different temperatures.

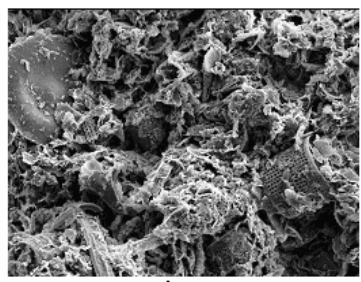

a)

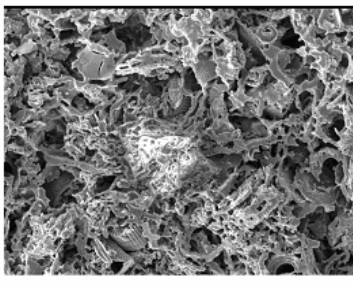

c) $50 \mu \mathrm{m}$

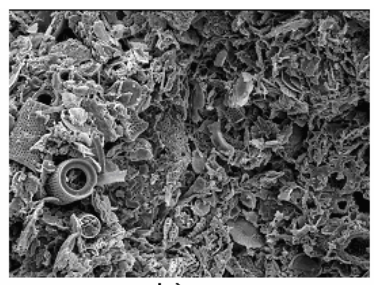

b) $50 \mu \mathrm{m}$

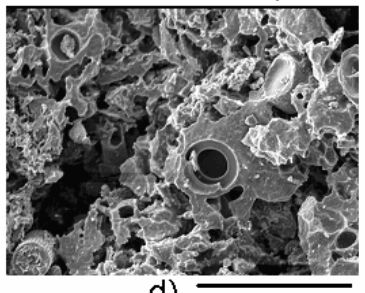

d)
$50 \mu \mathrm{m}$

FIGURE 4. SEM pictures of diatomite samples sintered at: a) $800^{\circ} \mathrm{C}$, b) $1100^{\circ} \mathrm{C}$, c) $\left.1200^{\circ} \mathrm{C}, \mathrm{d}\right) 1300^{\circ} \mathrm{C}$.

No change in the macroscopic structure can be observed after sintering diatomite samples at 800 and $1100^{\circ} \mathrm{C}$. However, the coalescence of porous diatom structure starts and the size of smaller pores decreases. At $1300^{\circ} \mathrm{C}$, the sintering of diatoms is obvious.

\section{X-Ray Diffraction}

Figure 5 shows the X-ray diffraction (XRD) pattern of 48 vol.\% clay based samples sintered at different temperatures. 


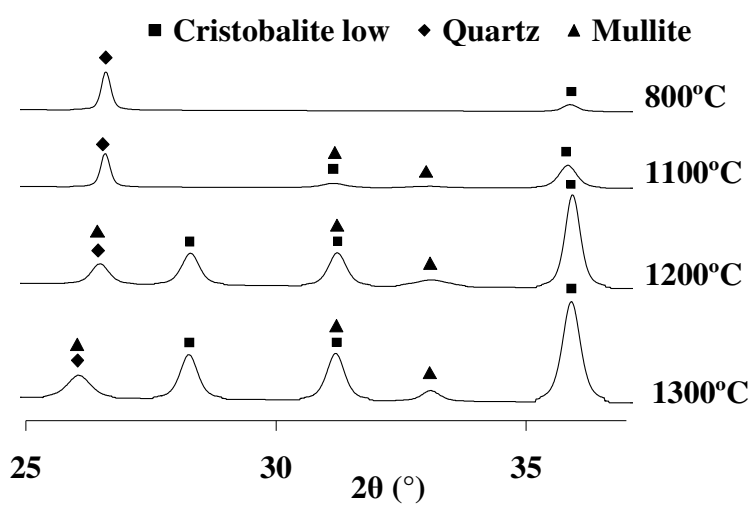

FIGURE 5. XRD pattern of diatomite-clay samples sintered at $800,1100,1200$ and $1300^{\circ} \mathrm{C}$.

Clay starts to transform into mullite (orthorhombic crystal lattice) at $1100^{\circ} \mathrm{C}$ which is in a good agreement with the literature [8]. At $1300^{\circ} \mathrm{C}$, mullite spinnels of approximately $1 \mu \mathrm{m}$ are observed at higher resolution with SEM. A transformation from the amorphous phase of diatomite to $\alpha$-cristobalite is observed with increasing sintering temperature. This corresponds with the results of Zhang et al. who showed that for diatomite earth, crystalline quartz peaks increase as the content of amorphous $\mathrm{SiO}_{2}$ decreases with the increase of sintering temperature [9]. He demonstrated that peaks appeared at $1150^{\circ} \mathrm{C}$, proving that cristobalite phase was formed. At $1250^{\circ} \mathrm{C}$, all amorphous $\mathrm{SiO}_{2}$ was converted into crystalline phase and mainly into cristobalite. San and Özgür explained that $\alpha$ cristobalite was undesirable in thermal environments due to the instability of alpha crystallisation [10]. However, influences of mullite formation are more pronounced on the attrition resistance than cristobalite

\section{Attrition resistance behaviour}

Attrition tests were performed on materials sintered at different temperatures.

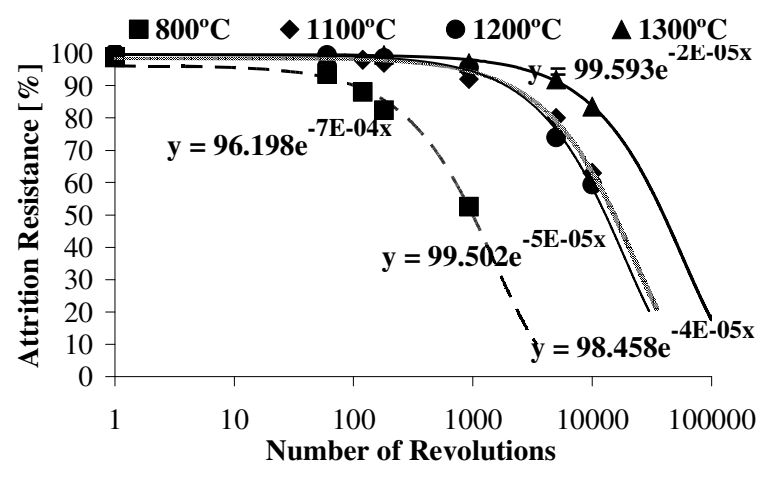

FIGURE 6. Influence of the sintering temperature on attrition resistance.

Attrition in a milling apparatus is enhanced by impact and friction. As seen in Fig. 6, attrition resistance is highly dependant on sintering temperature. However, no significant difference occurs between 1100 and $1200^{\circ} \mathrm{C}$, this can be explained by the phase transformation, as seen in XRD results. For all our experiments done on diatomite based materials, we found out that attrition properties follow a slightly exponential behaviour.

\section{Attrition resistance index}

Due to the significantly different attrition behavior it is very difficult to compare the results of all tests at a fixed number of revolutions. For example below 100 revolutions no significant difference between the materials could be observed. Above 10'000 revolutions the $800^{\circ} \mathrm{C}$ samples are almost completely ground. Therefore by using the exponential values obtained from the exponential equation of attrition resistance tests (attrition resitance index), the results of the attrition tests could be compared. The autors defined this exponent as the attrition resistance index (ARI) and it is shown Fig. 7. 


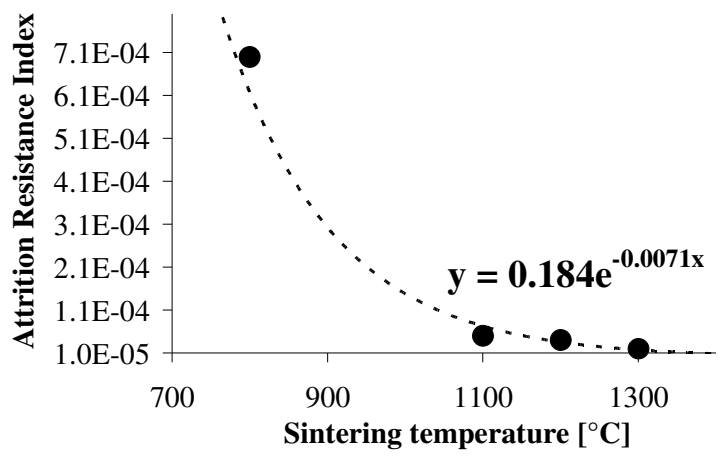

FIGURE 7. Plotting of the exponential index (ARI) vs sintering temperature.

The higher the attrition resistance, the lower exponential value (ARI) of the granulates is. Therefore increasing sintering temperature will lead to a significant increase of the attrition resistance. This plot allows the prediction of the attrition of a material independently of the grinding time.

\section{CONCLUSIONS}

The purpose of this work was to determine the influence of sintering temperature on microstructure and on attrition resistance of highly porous diatomite based materials. Chemical phase transformation of the material starts between 800 and $1100^{\circ} \mathrm{C}$.

As expected total porosity decreases with increasing sintering temperature. However, the average pore size increased with increasing sintering temperature. This is explained by sintering phenomenon: fine pore structure of the diatomite particle disappears due to the densification and coalescence at temperatures above $1100^{\circ} \mathrm{C}$. The pore structure between the sintered diatomite and the transformed clay does not significantly change up to $1300^{\circ} \mathrm{C}$ and therefore mean pore size increases. At 800 and $1300^{\circ} \mathrm{C}$ an average pore size of 1.6 and $5.7 \mu \mathrm{m}$ respectively could be observed.

$\mathrm{X}$-ray patterns showed the transformation from clay to mullite at $1100^{\circ} \mathrm{C}$ which is in good agreement with the literature. Crystallisation of amorphous silica into $\alpha$-cristobalite occurs at temperature above $1100^{\circ} \mathrm{C}$. Indeed at $1300^{\circ} \mathrm{C}$, phase transformation to mullite and the formation of cristobalite and quartz results in an increase of the attrition resistance of the granulates.
Using a serie of attrition tests with different amount of revolutions (attrition time), it was possible to estimate for each material an exponential attrition resistance index (ARI). A lower ARI is linked to a higher attrition resistance of the highly porous diatomite granulates. This plotting results in a time independent overview of attrition resistance of significantly different attrition resistant materials.

\section{ACKNOWLEDGMENTS}

This work was supported by the Competence Center Energy and Mobility (CCEM) research program of Switzerland.

\section{REFERENCES}

1. D. Losic, J.G. Mitchell and N. Voelcker, Adv. Mater. 29, 2947-2958 (2009).

2. J.Z. Liang, Polymer testing 8, 936-940 (2007).

3. H. Aderdour, A. Bentayeb, A. Nadiri, A. Ouammou, J.C. Sangleboeuf, A. Lucas-Girot and C. Carel, J.Phys. IV France 4, 361-364 (2005).

4. C.R. Bemrose and J. Bridgwater, Powder Tech. 2, 97126 (1987).

5. O.D Neikov, S.S. Naboychenko and G. Dowson, "Mechanical crushing and grinding" in Handbook of non-ferrous metal powders, edited by Elsevier Science \& Technology, 2009, pp. 47-62.

6. M. Stein, J.P.K. Seville and D.J. Parker, Powder technology 2, 242-250 (1998).

7. J. Rouquerol, D. Avnir, C.W. Fairbridge, D.H. Everett, J.H. Haynes, N. Pernicone, J.D.F. Ramsay, K.S.W. Sing and K.K. Unger, Pure Appl. Chem. 66, 1739-1758 (1994).

8. C.J. McConville and W.E. Lee, J. Am. Ceram. Soc. 88, 2267-2276 (2005).

9. X. Zhang, X. Liu and G. Meng, J.Am.Ceram.Soc. 7, 1826-1830 (2005).

10. O. San and C. Özgür, Journal of Alloys and compounds 1-2, 920-923 (2009). 